\title{
Fostering mature purpose beyond the classroom: considering family and other institutions in agentic purpose commitment
}

\author{
Promovendo projetos de vida maduros além da sala de \\ aula: o papel da família e de outras instituições no \\ compromisso com um projeto de vida agente
}

Timothy Scott REILLY ${ }^{1}$ (ID) 0000-0003-4329-6983
Jenni Menon MARIANO2 ${ }^{\text {ID }}$ 0000-0003-4379-4739

\begin{abstract}
This article addresses two questions about purpose in life: what is mature purpose, and how can it be cultivated? We first outline a picture of mature purpose based in part on established purpose research, and point out new frameworks that can resolve missing pieces and tensions in the current paradigms. We contend that above and beyond fulfilling discrete criteria present in operational definitions, mature purpose requires agentic yet flexible commitment to worthy goals rather than simplistic adoption of expected goals. A review of purpose formation beyond the classroom identifies similar roles of parents, post-secondary educational institutions, and extracurricular activities for supporting development of mature purpose in the direction of agentic commitment, namely, encouraging processes of: active exploration, tentative commitment, and support in navigating and sustaining meaningful commitment.
\end{abstract}

Keywords: Institutions; Maturity; Parenting; Purpose; Roles.

\section{Resumo}

Este artigo aborda duas questões sobre projetos de vida: o que são projetos de vida e como podem ser cultivados? Primeiramente, esboçamos um quadro de projetos de vida maduro baseado em parte na pesquisa de projetos de vida estabelecida e apontamos novas estruturas que podem resolver as peças que faltam e as tensões nos paradigmas atuais.

1 Ave Maria University, Department of Psychology, Moral and Spiritual Development Laboratory. 5050 Ave Maria Blvd., Ave Maria FL 34142, United States. Correspondence to T. S. REILLY E-mail: <timothy.reilly@avemaria.edu>.

2 University of South Florida, College of Education, Department of Educational and Psychological Studies. Sarasota, FL, United States.

$\boldsymbol{\nabla} \nabla \mathbf{v}$

How to cite this article

Reilly, T. S. \& Mariano, J. M. (2021). Fostering mature purpose beyond the classroom: considering family and other institutions in agentic purpose commitment. Estudos de Psicologia (Campinas), 38, e210115. https://doi.org/10.1590/1982-0275202138e210115 
Afirmamos que, acima e além de cumprir critérios discretos presentes nas definições operacionais, projetos de vida maduros requerem um comprometimento agente, porém flexível, com metas dignas, em vez da adoção simplista de metas esperadas. Uma revisão da formação de projetos de vida além da sala de aula identifica papéis semelhantes de pais, universidades e atividades extracurriculares para apoiar o desenvolvimento de projetos de vida maduros na direção do compromisso agente, a saber, processos de incentivo de: exploração ativa, compromisso experimental e apoio em navegar e manter um compromisso significativo.

Palavras-chave: Instituições; Maturidade; Parentalidade; Projetos de vida; Papéis.

Developmental scientists hold a variety of perspectives. However, all developmental perspectives imply an end state - a person-centered telos - which trends toward capabilities that are optimal, advanced, or relevant - in short, mature. In this article, we examine problems about the maturation of purpose in the life of the individual, beginning with the basic question, what is "mature" purpose? Once we have a grasp on mature purpose, an inevitable second question is how can mature purpose be fostered?

For the individual, an identified purpose is tied to positive outcomes (Damon et al., 2003). Some forms of purpose may be more indicative of the individual's well-being and thriving than are less advanced forms (Burrow et al., 2010). In spite of this progress in validating models of mature purpose, resolving the first question, what is mature purpose in the life for the individual? will require examining and then expanding current research frameworks. We contend that above and beyond fulfilling discrete criteria present in operational purpose definitions, there are process issues. A core process issue is that mature purpose requires agentic yet flexible commitment to worthy goals rather than totalitarian adoption.

So far, this idea of mature purpose that we propose is only partially examined in the research. As such, to enrich this conversation we discuss two current developmental research paradigms that serve as guideposts to mature individual purpose: youth purpose forms and adolescent identity development. Consequently, we discuss some solutions to the tensions that are emerging within these two areas of research but then offer some more ideas to make progress. Further, we consider virtue ethics as a fruitful philosophical approach for informing these programs of research. In this, we intentionally adopt various possible conceptions of maturity without necessarily preferring one to others, allowing for competing hypotheses. Such competing hypotheses allow for different conceptions to be considered simultaneously, and independently related to outcomes, supporting theory development.

Further, we also ask what principles and practices can foster mature purpose? Some work has been conducted on purpose formation in formal educational contexts to date, such as schools (Hatchimonji et al., 2019; Tirri, et al., 2019). To obtain a broader picture outside of the classroom, we will examine research on the development of purpose through collegiate programs (Clydesdale, 2015; Sullivan, 2016), pre-collegiate extracurriculars and other out-of-school activities (Larson et al., 2019), and parent and family relationships (Malin et al., 2014). These venues, we discover, offer similar insights into processes that support youth in developing mature purposes. Our intent is that these findings will give adults and educators some principles for helping young people foster mature purpose in their lives as they emerge into adulthood.

\section{Research evidence for mature purpose}

We consider purpose to be a stable, generalized, self-transcendent and personally meaningful long-term pursuit (Damon et al., 2003). By this definition, purpose is a meta-capability with multiple converging facets. The complexity of purpose alone it seems, requires considerable expertise in intrapersonal skills (Moran, 2009). Also, youth is formative for the development of purpose (Damon et al., 2003). So, the

2 experiences of adolescents and emerging adults provide valuable information about mature capabilities. 
Young people are good sources of information about purpose formation, not because they are mature, but precisely because they are on the cusp of maturity. Larson (2006) captures the co-occurring risks and potentials for developing purpose during adolescence. On one hand, new biological and social motivations arise which distract many young people from forming good purposes, if they develop purpose at all (Damon, 2008). On the other hand, new psychological and social capabilities emerge during adolescence enabling formation of purpose and ways to live it in the world (Larson, 2006). With these new capabilities, some youth do in fact achieve a sense of purpose. The diversity of the experiences of this group as they grapple with purpose can sharply distinguish between less and more advanced developmental capabilities.

\section{Purpose forms research}

One picture of "mature" purpose may be found in descriptions of qualitatively different purpose "forms" or "statuses". Such descriptions assume that a more fully formed purpose is one that includes the presence of personally meaningful goals, beyond the self-intentions, and active engagement; and these psychological and behavioral facets must be observed together in young people's accounts (i.e., as suggested by Damon et al.'s, 2003, definition of purpose). As such, in these accounts, interview responses are coded for all three facets of the definition (i.e., called a "beyond-the-self purpose" form; see Malin, 2018), whereas less advanced forms include only part of the definition (i.e. "self-oriented", "dreamer", and "dabbler" forms). In fact, for some researchers only beyond-the-self purpose would be considered purpose at all. To date, this approach has been replicated in multiple countries (e.g., Brazil, China, Singapore, and the United States). Not surprisingly, higher percentages of older adolescents and young adults exhibit the beyond-the-self purpose form in the cross-sectional interview studies than their younger counterparts. The progression from lower to higher forms however is not linear within most subjects - perhaps due to the complexity of purpose and the varied goals that all youth have (Malin et al., 2014).

Fulfillment of these three criteria of personally meaningful intentions, beyond-the-self motives and engagement do not by themselves describe the upper limits of purpose maturity: young purpose exemplars exhibit the criteria in sharper intensity, through sustained and intense involvement with causes beyond themselves, such as serving environmental sustainability, improving public health, or furthering the arts (Bronk, 2012; Mariano et al., 2021). Instead, adult purposeful moral exemplars and creative exemplars may serve as better models for the heights of mature purpose (Colby \& Damon, 1992; Damon \& Colby, 2015; Frimer \& Walker, 2009; Reilly, 2018).

Interviews are the classic approach in purpose forms research, but a few survey studies use the same grouping criteria often with factoring or clustering methods (Bronk \& Finch, 2010). In much of this research, mature purpose clusters correlate more strongly with positive outcomes than do the less mature categories (Bronk \& Finch, 2010). Pertinent to this special issue are country-specific variations: In Brazilian studies, feelings, emotions, and values are emphasized more as a part of mature purpose, acting in concert with cognitive capacities (Arantes et al., 2014; Arantes et al., 2017; Araujo et al., 2014).

\section{Moral purpose as mature purpose}

Allow us to assert again that a full picture of mature purpose entails more than the mere fulfillment of discrete criteria. Processes by which one selects purposes, commits to them, and then pursues them may matter for both ethical and psychological reasons, and many of the processes for mature purpose have yet to be fully explored. According to some purpose researchers, and to moral theorists (i.e., virtue ethicists), there is a moral component to mature purpose, which goes beyond selecting good goals, but also pursuing them 
in the right way, at the right time, and for the right reasons (Mariano et al., 2021). Purpose researches have written about "moral" purpose in this light, (often exchanging the term "moral" for "noble" or "prosocial", and distinguishing such purposes from less noble goal pursuits). In other views, virtuous maturity emerges not just from purpose identified or sought, but rather arises as a function of the moral maturity of the actor, which shapes their dispositions, excellences, and pursuits (Reilly \& Narvaez, 2018), nested within the broader culture and narratives of their tradition (Maclntyre, 2016). This view of virtuous maturity has been applied to purpose and validated in some research. For example, there is a positive association between purpose and character strengths during adolescence (Malin et al., 2017).

Some purpose researchers are aware of this point, as shown in a few studies and papers that indicate or theorize a positive relationship of purpose with indices of character, or virtue (Malin et al., 2017; Schnitker et al., 2019). Going further, case studies find that young people who exhibit mature purpose forms also describe strengths of gratitude and compassion in more universal terms than young people with less mature purpose forms (Malin et al., 2017). This research suggests that purpose maturity and virtuous maturity align. Perhaps, complementary definitions are in order so as to clarify this point. These definitions might consider the upper limits of mature purpose in moral terms as applied to aims (transformation or continuation of the world beyond the self) and breadth (local or global). For instance, Noguchi et al.'s (1992) concept of "twofold moral purpose" means that the individual pursues goals that are good for their own highest personal development and as directed to the service to all of humanity.

\section{Identity commitment processes and mature purpose}

Moral purpose, as we describe it above, is a how, or process issue (i.e., how one goes about pursuing their purpose so that good means align with good ends). But it is not the only process issue that figures in what we deem to be mature purpose. Another one is how individuals go about making commitments to a purpose in the first place. Recall that we asserted earlier that agentic selection and commitment are criteria for mature purpose in our view. Therefore, an account of how an individual has and is committing to purpose(s) is important in assessing the maturity of each purpose and purposeful adolescent.

Youth often totalize, seeing the world in terms of narrow absolutes (Erikson, 1968). Similarly, ideologies held narrowly tend toward totalitarianism, reducing the world to the ideology and absolutizing one value. While many ideologies compete for attention in the contemporary world, a leading ideology is that of homo economicus, the rational actor oriented toward maximizing utility, as a future worker and consumer, contributing to what philosopher Pieper (2009) has called an ideology of 'total work'. In this ideology all activity is oriented toward and evaluated on the basis of utility, leading to a denigration of anything without a determinate utility (whether work, academics, or otherwise). Mature purpose, however, requires a more nuanced and complex view of the world, in which one's place in the world is not reduced to a totalized view of the self or participation in a totalitarian ideology. Purpose instead emerges from a self making meaningful commitments that are flexibly integrated with the social world.

\section{Identity status theory and purpose}

The process of commitment is outlined well by Identity Status Theory (Marcia, 1966), which finds its precursor in Erikson's (1968) classic work on identity development. This approach suggests that a healthy identity emerges from self-understanding and consideration of one's commitments. Such self-understanding requires thinking about one's values and goals, exploring them and, with time, committing to and integrating these values and goals (we take this to be well aligned with self-concordance theory and self-determination 
theory: see Sheldon et al., 2020 for more on these theories). Through successful resolution of this identity decision-point (crisis), the young person can make healthy identity commitments in a number of domains: intellectual, political, spiritual, religious, vocational, and relational. However, such resolution is not to be taken for granted. Many young people form unhealthy identities, in one or more domains, and the development of an integrated and agentic purpose, directing one's identity toward a good beyond oneself is especially rare (Damon, 2008). Commitment, then, is a vital aspect of mature purpose, both in its direction and process. Purpose commitment processes mirror and complement identity development processes in a few studies (Burrow et al., 2010).

But there may be more to the story. Imagine if you will a situation in which a person fulfills all features of Damon et al.'s (2003) purpose definition, including a pro-social and beyond-the-self component: they have adopted clear goals which they claim are personally meaningful, and these goals are intended to affect others positively. They are acting on these goals. For all we know, this individual exhibits a mature sense of purpose. What is missing from this equation however is evidence about the degree to which the individual feels a sense of ownership for the purpose, as shown by the quality of their commitment process. Further, this individual may have a 'fragile' purpose, which falls apart when the situation changes or a role ends, indicating instability and a potential lack of generalizability, lacking the adaptive expertise characteristic of virtuous maturity (Reilly \& Narvaez, 2018).

\section{Identity control theory and purpose}

Distinctions between sociological and psychological accounts of identity may tell us more. Sociological Identity Commitment (SIC), emerging from Identity Control Theory (Stets \& Burke, 2003) emphasizes the role of interactions with others, so long as those interactions are relevant to an identity. Thus, if a young person is in a leadership role, with dozens of other youth supporting them, and serving hundreds as they plan an event, say a high school dance, there is likely to be strong SIC, with others holding them accountable to the role. Psychological Identity Commitment (PIC), in contrast, is primarily a result of internalized and ideological adoption of a role, belief, or goal, relating to Identity Status Theory (Meeus et al., 2010). Thus, one might have strong SIC without meaningful PIC (if one is engaged in an activity to please others without a personal interest) or strong PIC without SIC (if others aren't involved in one's identity-related behaviors).

The interplay of these two processes is central then to the development of purposes, which can be understood as particular kinds of identities (Burrow et al., 2010; Hill \& Burrow, 2012), specifically those that are self-transcendent, personally meaningful, and prospective. These identities, drawing on personality psychology, may serve to organize an individual's pursuits and structure the stories they tell about their lives (McAdams \& Guo, 2014, 2015). These stories likely draw on existing narratives, emerging from family and other stories that adolescents know, reflecting SIC, but also include a personal or individualized expression. Recent work on identity development provides additional insight into mature structures and processes underlying such narratives.

\section{Reconsideration and individualization}

Identity Status research, building on Marcia's (1966) dimensions of exploration and commitment, has begun to evaluate reconsideration, noting that adolescents often commit to identities in flexible and impermanent ways (Meeus et al., 2010). Reconsideration enables adaptive change, with adolescents adjusting to new information and experiences. This leads to a five-type taxonomy of identity statuses, emerging from cluster analysis (Crocetti et al., 2012). This includes (1) identity diffusion, lacking exploration, commitment, 
and reconsideration, and (2) early closure, with commitment in the absence of in-depth exploration or reconsideration. In addition, (3) moratorium, with reconsideration in the absence of commitment and with only moderate exploration and (4) searching moratorium with concurrent moderate commitment, exploration, and reconsideration are possible. Finally, (5) achievement follows after exploration, with high commitment and low reconsideration. Generally, there may be a trend away from diffusion and searching moratorium, which are more common in early in adolescence, and toward achievement (Meeus et al., 2012). It is worth noting that early closure, searching moratorium, and achievement may all be purposeful, despite their differing associations with psychosocial maturity.

Individualization theory seeks to make sense of heightened social demands to show initiative and agency needed in the contemporary transition to adulthood (Schwartz et al., 2005). "Default individualization" occurs when a young person passively goes along with social norms and expectations of their context uncritically, taking the 'easy road'. "Developmental individualization", in contrast, entails an active, personal, and critical consideration of who one desires to become, which is a more psychologically challenging and proactive path. Here as with Identity Status Theory, the active and critical approach is associated with better developmental outcomes and greater maturity.

\section{Purpose and maturity summary}

The theories articulated here are valuable in considering scholarship on purpose, not only because of apparent parallels between identity formation and purpose (Burrow et al., 2010; Hill \& Burrow, 2012), but also to provide a richer consideration of forms that mature purpose may take. For instance, an adolescent may espouse a purpose, but do so in a manner that manifests early closure rather than achievement. In terms of individualization theory, an adolescent may have a default purpose, meaningful to the self, but without the initiative and depth characterizing a developmentally individualized purpose. If all purposes are 'equal', then these distinctions may be beside the point. However, it seems plausible that some purposes are more developmentally adaptive or mature than others, and these are likely characterized by features highlighted in Identity Status Theory (Meeus et al., 2010), individualization theory (Schwartz et al., 2005), and moral purpose in light of virtue ethics (Mariano et al., 2021) in addition to the consideration of purpose forms (Malin et al., 2014). Drawing on Identity Control Theory (Stets \& Burke, 2003), a more mature purpose may also serve to integrate various SIC and PIC into a personal narrative that is at once coherent to the self and valued by others.

\section{Contexts supporting mature purpose}

Against this backdrop, which outlines processes for mature purpose, we can begin to systematically consider the role of families, collegiate programs, and extracurricular activities in the development of purpose. For young people, at least two sources that provide material for commitment are apparent: the social structure and the individual's own personal agency (Moran et al., 2013). On one hand, society offers a multitude of narratives for young people about self, and purpose. These narratives offer 'default' life paths for many, but within these offerings of their individuals must learn to authentically navigate a meaningful, and self-authored purpose. One way through these tensions between structure and agency, we contend (Maclntyre, 2016), emerges from consideration of the cultural narratives, traditions, and expectations that young people experience and engage with. Other narratives, expectations, and patterns of relationship however, may be more likely to foster the personal agency necessary for sustained purpose. This can seem, retrospectively, to be happenstance, but, as Krumboltz (2009) and Bandura (1998) note, such seeming 'good luck' can emerge from particular manifestations of agency. 
These contexts provide various manifestations of sociological identity commitment, and through this may contribute to particular manifestations of psychological identity formation and commitment. The organizing question emerging from this is: what characterizes families, collegiate programs, and extracurricular activities that are supportive of mature purpose, rather than the absence of purpose or less mature forms of purpose?

\section{Parents and Families}

In addressing parents and families, one challenge is understanding general processes that may be supportive of purpose and other processes that may be especially aligned with purpose formation. Generally, parenting, in the form of authoritative parenting that is supportive of secure attachment is adaptive for young people. Research on purpose, and spiritual development, sheds some additional light on particular processes that may be especially fruitful for parents seeking to foster purpose in their children.

Supporting secure attachment (Mikulincer \& Shaver, 2007) and adopting authoritative parenting (Huta, 2012) are well established factors in supporting the positive development of young people. Secure attachment is fostered by responsive and well-attuned parenting, neither overprotective, nor excessively distant. Secure attachment supports engagement in exploration and healthy relationships (Mikulincer \& Shaver, 2007). Authoritative parenting is understood to be multifaceted, incorporating demandingness -high expectations, warmth and acceptance -high support, and autonomy support -assisting the child in making adaptive decisions without parental demands (Roth, 2008). Autonomy support, given its association with prosocial tendencies and internalization of motivation, may be especially valuable in helping youth to move beyond default identities and pursuits and toward personally meaningful purposes.

Parents and families play an especially important role in fostering purpose (Malin et al., 2014) and spirituality more broadly (Dollahite et al., 2019). Especially in early adolescence, parents support purpose by encouraging their children to enact self-transcendent agency and to think about the impact and importance of such agency. Similarly, parents may be valuable in supporting children in extracurricular involvements, central to purpose in mid-adolescence. This support could be direct, actively encouraging these involvements, or indirect, providing economic support and privileges, allowing children the opportunity to pursue these commitments without other after school commitments. Finally, parents and family can provide consistency for young people in the transition to and from college, helping them to sustain their purposeful pursuits during these often tenuous periods.

These findings parallel in many ways what Dollahite et al. (2019) research on family processes in religious and spiritual development. For instance, religiously or spiritually engaged children come from families with parents who listen to and engage with their spiritual and religious questions, alongside relating these questions to other facets of the child's life. These parents also encourage children to turn to religious and spiritual resources to deal with stresses, facilitating religious exploration. These children also look to their parents as models for how to respond to challenges. Parents in these families also emphasize commitments to consistency, authenticity, and serving as an example to their children in the religious or spiritual tradition, at once providing caring support and teaching the values and practices of their tradition.

\section{Collegiate programs}

The idea that college and other forms of post-secondary education are a space to decide upon and prepare to pursue one's purpose may be as old as the religious roots of universities in North African, Middle Eastern and European culture (e.g., Maclntyre, 2011). The ongoing rise of the technical university model over 
and against the liberal arts model in higher education, as demonstrated by shifts in faculty disciplines (Frank \& Gabler, 2006) among other shifts, have been dramatic, especially in the period since the Second World War. The technical university model professionalizes education, with a focus on education as preparation for future work. In contrast, the much older liberal arts tradition, focuses on education as a process of formation in being human, with much greater emphasis on the humanities (Sullivan, 2016).

Liberal arts colleges and liberal arts curricula, within larger universities, still play a major role in contemporary education in the United States, though less so elsewhere in the world. Further, some major initiatives in the last two decades have begun to re-emphasize the place of formation in purpose for collegiate education (especially the Program for Theological Exploration of Vocation (Clydesdale, 2015; Sullivan, 2016)).

Research on the Program for Theological Exploration of Vocation and similar campus initiatives finds several key structural characteristics of vocational/purpose exploration programs: (1) the theme of and emphasis on vocational/purpose exploration itself, (2) encouraging communities of learning, and (3) offering space for reflection (Sullivan, 2016). Vocational/purpose exploration served to encourage self-transcendent motives for learning and self-development and broader sense of what is meaningful. Communities of learning served as spaces for conversation and action, allowing students to both more fully understand and try out the purposes they were exploring. Further, these communities worked to integrate classroom experiences with the rest of college life. Finally, paralleling research on service learning and moral identity (Matsuba et al., 2014), the role of reflection, at an individual and collective level, helped individuals to develop an integrative sense of the meaning of their actions, now and in the future, and the roles and values of their communities as well.

This does not mean that simply creating the structure for a purpose exploration program is sufficient. Instead, various factors within these programs influence efficacy, according to Clydesdale (2015). These include alignment of the program with the history and traditions of the campus, the selection of staff who are especially suited to the social challenges of such programs, and timing interventions and programming optimally (also a key factor in social psychological interventions, see Walton \& Yeager 2020). It is worth noting that Clydesdale (2015) emphasizes quantifiable benefits beyond purpose, in the form of heightened collegiate retention and success, resulting from these programs as well. Further, these suggestions are not unique to liberal arts education, but have been proposed as important to professional education more broadly (Colby et al., 2011). As such, they can be applied even in settings where American-style liberal education is not the dominant practice. This is especially the case as while there is a classroom component, many of these programs are about campus experiences more broadly. This does, however, leave room for deeper consideration of how to provide these opportunities in non-residential higher education settings.

\section{Extracurriculars and out-of-school engagements}

School is for many young people a time and space to build skills. Yet, secondary education classes are generally primarily about knowledge transmission and academic accomplishment. Extracurricular and community involvement provide opportunities for sustained and meaningful engagement (Bundick, 2011) with particular roles, activities, and communities (Larson et al., 2019; Malin et al., 2014).

There are a number of ways that these engagements can support purpose (Malin et al., 2014). They may help an individual to identify as part of something larger than themselves (e.g., serving the community). They also provide structure for developing and exploring ways of being in and contributing to the world, often alongside peers. Finally, these activities often involve support from various adult mentors, which can assist in children's commitment to a domain, especially in the absence of parental support or expertise (Larson 8 et al. 2019). 
Larson and colleagues (2019) consider four facets through which youth programs support positive youth development, including the development of purpose. These steps are (1) taking on a role, (2) experiencing role demands, (3) fulfilling role demands, and (4) developmental change over extended engagement. In taking on roles, even when these roles are assigned, youth generally saw these roles as meaningful, interesting opportunities to grow and to realize their intention to make a difference. Role demands include both situational challenges, involving interactions with peers or with those served by the program, and motivational challenges, including stress, strain, and reconsideration of commitment to the program. Related to this, motivation served to support youth in fulfilling these role obligations amidst the stresses, and social supports, from adult leaders and peers, helped youth to navigate and sustain their engagement. Finally, the developmental change youth experienced emphasizes the integration of action and social responsibility, paralleling the reconciliation model of moral centrality development (Frimer \& Walker, 2009), with action being for social (self-transcendent) ends.

Indeed, in many ways these extracurriculars parallel the programmatic emphasis suggested by successful collegiate programs. They are sustained, holistic, and relational. They are spaces in which there is opportunity to both practically engage with and prepare for purposeful pursuits and to explore different means of realizing a purpose. Further, they provide a community with specific goals and with other people with whom to converse and learn how to pursue one's purpose(s).

\section{Discussion}

In this article, we have outlined frameworks for mature purpose suggested by a current definition and by moral and social scientific perspectives, and we described some research that operationalize these perspectives. We propose a complementary view of mature purpose as agentic and flexible commitment that is personally meaningful, and oriented beyond-the-self, showing how it is supported by theories of identity, virtue, and individuation. We then examined how mature purpose can be fostered by family, collegiate programs and extracurricular and out-of-school time contexts. One emergent theme that we discovered is that the three different settings can function in quite similar ways to support young people's mature purpose development, namely by (1) encouraging exploration, (2) encouraging flexible commitment to self-transcendent motives, and (3) providing social support to develop the skills and motivations needed to be successful in pursuing nascent commitments.

For example, encouraging exploration is important to help young people avoid defaulting into a particular identity or commitment, perhaps as the result of encouragement or pressure from family, friends, or institutions. Furthermore, while we have observed that the form that exploration takes changes over the course and across contexts of development, active exploration may be preferable in all cases. Amidst this, roots in attachment play a role in such exploration, supporting individuals as they try new things. Exploration is encouraged in part by expectations of individualization, that individuals will move beyond the family and contribute to the world in ways beyond academic performance and membership in groups. Exploration is also encouraged by the variety of activities, extracurriculars, and other programs available to adolescents, allowing them to choose different involvements, emerging from their interests.

Exploration, on its own, however, is not enough. Instead, tentative commitment is needed, and flexible commitment to purposes of interest can be encouraged. This commitment is often fostered by the demandingness of parents, requiring that children not give up at the first sign of difficulty. It is also fostered by roles and structures that require ongoing involvement, with the ups and downs that come from sustained engagements. Such commitment is further encouraged by relationships with other individuals and 
institutions, as an expression of adolescents valuing and desiring to sustain and further these relationships. Beyond this, parents and other settings can encourage youths' commitment to self-transcendent motives which are considered a feature of mature purpose: self-transcendence expresses the fruits of young people's relationships, drawing them even further into the world beyond themselves.

The third way that the settings we discuss help form purpose is through social supports. These provide practical tools and ideas for young people as they pursue self-transcendent commitments, along with emotional and motivational resources to continue these pursuits over time. Our consideration of the literature suggests that it can be difficult for adolescents to develop the skills, motivations, and relationships needed to navigate and sustain their commitments. As such, parental support, the support of other adult mentors (Larson et al., 2019), and institutional supports (Clydesdale, 2015; Sullivan, 2016) are all valuable. These supports can be technical, social and emotional, and/or self-regulatory. Technical supports assist adolescents in developing competence to complete particular tasks or to plan and execute long term projects. Social and emotional supports help adolescents to cope with the negative emotions that arise and to share the positive emotions of success with close others. Self-regulatory supports help adolescents to reconsider their commitments, to select the ways that they are most interested in contributing to their communities, and to sustain themselves at times when other sources of support may not be immediately available. Formal and informal reflection and conversations within institutions create spaces for these forms of support to help adolescents navigate their own decisions. In sum, each of the contexts we discuss here seem to, in the ideal case, foster social closure (Coleman, 1988). This social closure can be understood as sociological identity commitment toward eventual purposeful psychological identity commitment, which integrates the encouragement of personal and collective action and agency toward self-transcendent ends.

\section{Future directions}

Of course, the ability of any setting to foster a mature sense of purpose hinges on what is meant by mature purpose, and we have attempted to provide varied, if related, conceptions of mature purpose in this article. Future research should examine the relationship of the institutional settings mentioned to the formation of mature purpose, considering maturity according to the various theoretical models that we have described. Further, other conceptions of morality and psychological theories can be engaged, offering alternative visions of mature purpose. We also encourage additional inquiry into the words "stable" and "generalized" in the definition of purpose that is often used, as related to maturity (Damon et al., 2003). These words have received far less attention than other components of the definition. What kind(s) of stability and generalization constitute mature purpose? Stability can, of course, manifest as wrongheaded inflexibility, a concern in discussions of foreclosure and early closure in identity status theory. Similarly, generalization can be vague and permissive at one extreme, allowing any pursuit to 'fit' within one's purpose, with only a loose coherence. At the other extreme, an 'ungeneralized' self-transcendent and personally meaningful goal risks excessive specificity, likely leading to frustration or distress when avenues to pursue a narrow goal are closed.

More generally, in regard to the conceptions of maturity offered in this paper, we suggest that they are best understood as highlighting key features and considerations in evaluating and developing purposeful maturity. We also note that there is a need to explore the underlying psychological and social processes that are essential to reaching such maturity, and how each of them is best supported by contexts encouraging exploration, flexible commitment, and support in the pursuit of purposes. Additional research is needed to determine if one of these conceptions is better than others for understanding mature purpose as it relates to well-being, concurrently and longitudinally, and we encourage such inquiry. 


\section{Conclusion}

All developmental perspectives imply an end state - a person-centered telos - which trends toward advancement. The aim of this paper was to develop some perspectives on what advanced purpose may look like, using the concept of maturity, and then to identify promising practices for its cultivation in specific settings. As we have discovered, current research with young people guided by a popular definition point to features of mature purpose, such as when individuals are able to effectively integrate and coordinate active engagement and pro-social reasons with their personally meaningful goals across life: in this view, "maturity" is the ability to synchronize aspects of one's behavior, motivation, and moral intentions in pursuit of self-transcendent goals. Additionally, some formulations suggest that purpose maturity includes wise and good decisions about how, when, and why to pursue one's purposes, much akin to a virtues ethics approach. Nevertheless, to advance the conversation we have proposed that a framework of mature purpose should also use a mature commitment process, namely the ability to be discerning, agentic, and flexible in goal selection and commitment, rather than adopting goals received by others in a simplistic, or totalitarian way. Ideally, if armed with this understanding of purpose, educational institutions can undermine totalitarian thinking and help adolescents achieve a mature integration of their various identities and values as they form purposeful commitments. Another way to say this is that families and other institutions should support youth in participating, contributing, and thriving purposefully in thick cultures, with webs of complex meaning and stories, amidst a recognition that values and commitments are not always fully apparent or understood. If they do so, they will be able to lead youth out of thin cultures and childlike stories of surviving across disparate contexts in self-serving ways and into purposeful maturity.

\section{Contributors}

Both authors were involved in conceptualization, investigating and procuring sources, writing, and editing.

\section{References}

Arantes, V., Araujo, U., Pinheiro, V., Marimon, M. M., \& Sastre, G. (2017). Youth purpose through the lens of the theory of organizing models of thinking. Journal of Moral Education, 46(3), 245-257. http://dx.doi.org/10.1080/0305724 0.2017 .1345725

Arantes, V. A., Pinheiro, V. P. G., \& Araujo, U. F. (2014). Feelings and emotions in youth's purpose. Journal of Youth Development, 9(4), 1-10. https://doi.org/10.5195/jyd.2014.43

Araujo, U. F. D., Arantes, V. A., Klein, A. M., \& Grandino, P. J. (2014). Youth purpose and life goals of students engaged in community and social activities. Revista Internacional D'Humanitats, 30, 119-128. http://hdl.handle.net/11449/122383

Bandura, A. (1998). Exploration of fortuitous determinants of life paths. Psychological Inquiry, 9(2), 95-99. https://doi. org/10.1207/s15327965pli0902_2

Bronk. K. C. (2012). A grounded theory of development of noble youth purpose. Journal of Adolescent Research, 27(1), 78-109. https://doi.org/10.1177/0743558411412958

Bronk, K. C., \& Finch, H. (2010). Adolescent characteristics by type of long-term life aim. Applied Developmental Science, 14(1), 35-44. https://doi.org/10.1080/10888690903510331

Bundick, M. J. (2011). Extracurricular activities, positive youth development, and the role of meaningfulness of engagement. Journal of Positive Psychology, 6(1), 57-74. https://doi.org/10.1080/17439760.2010.536775

Burrow, A. L., O'Dell, A. C., \& Hill, P. L. (2010). Profiles of a developmental asset: youth purpose as a context for hope and well-being. Journal of Youth and Adolescence, 39(11), 1265-1273. https://doi.org/10.1007/s10964-009-9481-1

Clydesdale, T. (2015). The purposeful graduate: why colleges must talk to students about vocation. University of Chicago Press.

Colby, A., \& Damon, W. (1992). Some do care: contemporary lives of moral commitment. Simon and Schuster. 
Colby, A., Ehrlich, T., Sullivan, W. M., \& Dolle, J. (2011). Rethinking undergraduate business education: liberal learning for the profession. John Wiley \& Sons.

Coleman, J. S. (1988). Social capital in the creation of human capital. American Journal of Sociology, 94, 95-120. https:// doi.org/10.1086/228943

Crocetti, E., Schwartz, S. J., Fermani, A., Klimstra, T., \& Meeus, W. (2012). A cross-national study of identity status in Dutch and Italian adolescents. European Psychologist, 17(3). https://doi.org/10.1027/1016-9040/a000076

Damon, W. (2008). The path to purpose: helping our children find their calling in life. Simon and Schuster.

Damon, W., \& Colby, A. (2015). The power of ideals: the real story of moral choice. Oxford University Press.

Damon, W., Menon, J., \& Bronk, K. C. (2003). The development of purpose during adolescence. Applied Developmental Science, 7(3), 119-128. https://doi.org/10.1207/S1532480XADS0703_2

Dollahite, D. C., Marks, L. D., \& Wurm, G. J. (2019). Generative devotion: a theory of sacred relational care in families of faith. Journal of Family Theory \& Review, 11(3), 429-448. https://doi.org/1080/01494929.2018.1469575

Erikson, E. H. (1968). Identity: youth and crisis. W.W. Norton \& Company.

Frank, D. J., \& Gabler, J. (2006). Reconstructing the university: worldwide shifts in academia in the 20th century. Stanford University Press.

Frimer, J. A., \& Walker, L. J. (2009). Reconciling the self and morality: an empirical model of moral centrality development. Developmental Psychology, 45(6), 1669. https://psycnet.apa.org/doi/10.1037/a0017418

Hatchimonji, D. R., Linsky, A. C., \& Elias, M. J. (2019). Frontiers in youth purpose research. Journal of Character Education, 15(2), 7-18. https://www.proquest.com/scholarly-journals/special-issue-guest-editors-introduction/ docview/2309266995/se-2?accountid=34027

Hill, P. L., \& Burrow, A. L. (2012). Viewing purpose through an Eriksonian lens. Identity, 12(1), 74-91. https://doi.org/10.1 080/15283488.2012.632394

Huta, V. (2012). Linking peoples' pursuit of eudaimonia and hedonia with characteristics of their parents: parenting styles, verbally endorsed values, and role modeling. Journal of Happiness Studies, 13(1), 47-61. https://doi.org/10.1007/ s10902-011-9249-7

Krumboltz, J. D. (2009). The happenstance learning theory. Journal of Career Assessment, 17(2), 135-154. https://doi. org/10.1177/1069072708328861

Larson, R. (2006). Positive youth development, willful adolescents, and mentoring. Journal of Community Psychology, 34(6), 677-689. https://doi.org/10.1002/jcop.20123

Larson, R. W., Raffaelli, M., Guzman, S., Salusky, I., Orson, C. N., \& Kenzer, A. (2019). The important (but neglected) developmental value of roles: findings from youth programs. Developmental Psychology, 55(5), 1019-1033. https:// doi.org/10.1037/dev0000674

MacIntyre, A. C. (2011). God, philosophy, universities: a selective history of the Catholic philosophical tradition. Rowman \& Littlefield Publishers.

Maclntyre, A. (2016). Ethics in the conflicts of modernity: an essay on desire, practical reasoning, and narrative. Cambridge University Press.

Malin, H. (2018). Teaching for purpose: preparing students for lives of meaning. Harvard Education Press.

Malin, H., Reilly, T. S., Quinn, B., \& Moran, S. (2014). Adolescent purpose development: exploring empathy, discovering roles, shifting priorities, and creating pathways. Journal of Research on Adolescence, 24(1), 186-199. https://doi. org/10.1111/jora.12051

Malin, H., Liauw, I., \& Damon, W. (2017). Purpose and character development in early adolescence. Journal of Youth and Adolescence, 46, 1200-125. https://doi.org/10.1007/s10964-017-0642-3

Marcia, J. E. (1966). Development and validation of ego-identity status. Journal of Personality and Social Psychology, 3(5), 551-558. https://doi.org/10.1037/h0023281

Mariano, J. M., Damiani, T., \& Boyer, M. (2021). Self- and other-reported virtues of young purpose exemplars. Youth \& Society, 53(3), 466-489. https://doi.org/10.1177/0044118X19859022

Matsuba, M. K., Murzyn, T., \& Hart, D. (2014). Moral identity development and community. In M. Killen \& J. G. Smetana (Eds.), Handbook of moral development (2nd ed., pp. 520-537). Psychology Press.

McAdams, D. P., \& Guo, J. (2014). How shall I live? Constructing a life story in the college years. New Directions for Higher Education, 2014(166), 15-23. https://doi.org/10.1002/he.20091 
McAdams, D. P., \& Guo, J. (2015). Narrating the generative life. Psychological Science, 26(4), 475-483. https://doi. org/10.1177/0956797614568318

Meeus, W., van de Schoot, R., Keijsers, L., \& Branje, S. (2012). Identity statuses as developmental trajectories: a five-wave longitudinal study in early-to-middle and middle-to-late adolescents. Journal of Youth and Adolescence, 41(8), 1008-1021. https://doi.org/10.1007/s10964-011-9730-y

Meeus, W., van de Schoot, R., Keijsers, L., Schwartz, S. J., \& Branje, S. (2010). On the progression and stability of adolescent identity formation: a five-wave longitudinal study in early-to-middle and middle-to-late adolescence. Child Development, 81(5), 1565-1581. https://doi.org/10.1111/j.1467-8624.2010.01492.x

Mikulincer, M., \& Shaver, P. R. (2007). Boosting attachment security to promote mental health, prosocial values, and inter-group tolerance. Psychological Inquiry, 18(3), 139-156. https://doi.org/10.1080/10478400701512646

Moran, S. (2009). Purpose: Giftedness in intrapersonal intelligence. High Ability Studies, 20(2), 143-159. https://doi. org/10.1080/13598130903358501

Moran, S., Bundick, M. J., Malin, H., \& Reilly, T. S. (2013). How supportive of their specific purposes do youth believe their family and friends are? Journal of Adolescent Research, 28(3), 348-377. https://doi.org/10.1177/07435558412457816

Noguchi, L. M., Hanson, H., \& Lample, P. (1992). Exploring a framework for moral education. Palabra.

Pieper, J. (2009). Leisure: the basis of culture. Ignatius Press.

Reilly, T. S. (2018). Exemplarity and virtue. Philosophy, Theology and the Sciences, 5(2), 149-173. https://doi.org/10.1628/ ptsc-2018-0014

Reilly, T. S., \& Narvaez, D. (2018). Character, virtue, and science: linking psychological and philosophical views. Philosophy, Theology and the Sciences, 5(1), 51-79. https://doi.org/10.1628/ptsc-2018-0005

Roth, G. (2008). Perceived parental conditional regard and autonomy support as predictors of young adults' self-versus other-oriented prosocial tendencies. Journal of Personality, 76(3), 513-534. https://doi.org/10.1111/j.14676494.2008.00494.x

Schnitker, S. A., King, P. E., \& Houltberg, B. (2019). Religion, spirituality and thriving: transcendent narrative, virtue, and telos. Journal of Research on Adolescence, 29(2), 276-290. https://doi.org/10.1111/jora.12443

Schwartz, S. J., Côté, J. E., \& Arnett, J. J. (2005). Identity and agency in emerging adulthood: two developmental routes in the individualization process. Youth \& Society, 37(2), 201-229. https://doi.org/10.1177/0044118X05275965

Sheldon, K., Gordeeva, T., Sychev, O., Osin, E., \& Titova, L. (2020). Self-concordant goals breed goal-optimism and thus well-being. Current Psychology. https://doi.org/10.1007/s12144-020-01156-7

Stets, J. E., \& Burke, P. J. (2003). A sociological approach to self and identity. In M. Leary \& J. Tangney (Eds.), Handbook of self and identity (pp. 128-152). The Guilford Press.

Sullivan, W. M. (2016). Liberal learning as a quest for purpose. Oxford University Press.

Tirri, K., Moran, S., \& Mariano, J. M. (Eds.). (2019). Education for purposeful teaching around the world. Routledge.

Walton, G. M., \& Yeager, D. G. (2020). Seed and soil: psychological affordances in contexts help to explain where wise interventions succeed or fail. Current Directions in Psychological Science 29(3), 219-226. https://doi. org/10.1177\%2F0963721420904453 